\title{
El aporte del sistema biológico, psíquico y social a la construcción de la temporalidad en niños con VIH
}

The Contribution of the Biological, Psychic, and Social System to the Construction of Temporality in Children with HIV

Jessica Sánchez

Facultad de Ciencias Sociales, Universidad de Manizales, Colombia

RESUMEN

En el presente artículo se entiende la temporalidad como un proceso psicológico que el niño con VIH construye de forma autopoiética, con el aporte de tres sistemas: el sistema biológico, el sistema psíquico y el sistema social. Se adoptan los presupuestos epistemológicos de la teoría sistémica constructivista desarrollada por Luhmann, en el sentido que se asume que los niños con VIH están conformados por dichos sistemas autopoiéticos y que cada uno de estos sistemas, en un acoplamiento estructural, aporta en la construcción de su modelo de temporalidad.

PALABRAS Clave: Sistema biológico; Sistema psíquico; Sistema social; Niños con VIH;

Temporalidad

ABSTRACT

On this article, temporality is understood as a psychological process which children with HIV build in a autopoietic way, with the contribution of three systems: the biological system, the psychic system and the social system. The epistemological bases of the systemic theory developed by Luhmann are taken, in the way it assumes that children with HIV are formed with those autopoietical systems and each one of them, in a structural mating, contributes to the building of his/her temporality model.

KEYWORDS: Biological system; Psychic system; Social system; Children with HIV; Temporality

\section{INTRODUCCIÓN}

Este artículo se origina en el proyecto de investigación "La construcción de la temporalidad en niños y niñas con $\mathrm{VIH}^{\prime \prime}$, desarrollado en el Doctorado en Ciencias Sociales, Niñez y Juventud, del Centro de Estudios Avanzados en Niñez y Juventud, Universidad de Manizales - CINDE. Basa sus postulados en la Teoría General de Sistemas Autopoiéticos de Niklas Luhmann. En la investigación se trabajó con niños y niñas con $\mathrm{VIH}$, algunos de ellos declarados en adoptabilidad bajo custodia del Instituto de Bienestar Familiar (ICBF), sus madres biológicas y sustitutas, el equipo interdisciplinario encargado del manejo integral.

En el presente artículo, se intenta dar un salto transdisciplinario, poco común en las ciencias sociales, utilizando la teoría de sistemas autopoiéticos de Niklas Luhmann como operador epistemológico para leer los sistemas sociales y también los sistemas psíquicos y biológicos. Se habla

REVISTA MAD - REVISTA DEL MAGÍSTER EN ANÁLISIS SISTÉMICO APLICADO A LA SOCIEDAD ISSN 0718-0527

Facultad de Ciencias Sociales, Departamento de Antropología.

Universidad de Chile

$\underline{\text { www.revistamad.uchile.cl }}$

DOI: 10.5354/0718-0527.2017.46143 
de niños ya no como unidad antropológica, sino como un cúmulo de diferencias constituido por diversos sistemas (biológico, psíquico, social). Se propone una ruta comprensiva y alternativa de cómo la niñez podría ser abordada para entendimientos con pretensión de validez universal en ideas constitutivas de identidad, en tanto mutaciones del espacio.

Este artículo asume el riesgo de traer una teoría de la sociología, la Teoría General de Sistemas Autopoiéticos, que ha planteado lineamientos específicos para leer los sistemas sociales, a leer también los sistemas biológicos y psíquicos bajo la premisa de que este modelo alternativo podría ofrecer nuevas luces de cómo aporta cada uno de los sistemas en la construcción de los procesos psicológicos, entre ellos la temporalidad.

Luhmann hizo aportes novedosos al concepto de autopoiesis al extrapolarlo a las ciencias sociales; ahora se asume el reto de volverlo a traer a la biología y a la psicología para explicar cómo cada uno de estos sistemas aporta en la construcción de la temporalidad en niños con VIH. Por otro lado, también se asume el riesgo de afirmar que la temporalidad, como una de las acepciones de la palabra tiempo, no existe por fuera del niño, sino que se construye.

Se propone leer diferente a los niños con una condición específica, en este caso con VIH, y cuestionarse sobre los modelos que día a día se construyen en el sistema social. En los resultados de la investigación que dio origen al presente artículo se observó que los niños con VIH no perciben el tiempo de una forma diferente por tener una enfermedad crónica, ni se apoyan en ella para hablar de la temporalidad, porque han naturalizado la enfermedad, siendo esto un aporte importante al abordar poblaciones con condiciones específicas, en clave de diversidad e inclusión.

En la actualidad, es claro que los tres sistemas biológico, psíquico y social, aportan a la construcción de los procesos psicológicos, entre ellos la temporalidad, pero lo que aún no está claro es la manera como la información electroquímica que maneja el sistema biológico se convierte en información abstracta, como son los procesos psicológicos: la memoria, la atención, la percepción del tiempo..., y cómo estos, a su vez, aportan a que el ser humano logre construir su temporalidad, esa continuidad biográfica (pasado, presente y futuro) y la simultaneidad o la sucesión de los hechos.

La temporalidad como construcción abstracta requiere de los procesos biológicos y psicológicos y es influida por estos. Por ejemplo, para su construcción se requieren las emociones y la memoria como procesos psicológicos que intervienen en la capacidad del niño para rememorar y anticipar. Un niño con VIH que presenta alteraciones en su estado de ánimo a causa de su patología, del efecto secundario del manejo farmacológico, o por la manera cómo interpreta las informaciones provenientes del sistema social, tendrá cambios en todos sus procesos y esto se refleja en el pensamiento, en la conducta, en la actividad psicomotora, en las manifestaciones somáticas y en la manera como se relaciona con el entorno. En la memoria, por ejemplo, si el niño, aparte de su patología (VIH) cursa una 
depresión, podría tener un bloqueo en el pasado, si cursa una manía, tendría su presente desecho en instantes, y si su comportamiento es obsesivo, tendría el futuro enteramente predecible.

Lo anterior indica que las alteraciones en el sistema psíquico, es decir, en los procesos psicológicos, son derivadas de los cambios en el sistema biológico (en los procesos biofísico-químicos del sistema nervioso); y al ser el sistema biológico entorno del sistema psíquico y viceversa, ambos sufrirán cambios en la construcción de la información y en la manera como interpretan los estímulos procedentes del sistema social. El límite entre el cuerpo como organismo (sistema biológico) y la mente (sistema psíquico) aún no está claro, de modo que una aproximación a la comprensión de la manera como se construye la temporalidad brindaría aportes significativos para comprender la forma como se construyen los procesos psicológicos en general.

Para Luhmann (1998), los tres sistemas son autopoiéticos, con clausura operativa, que reproducen en su interior las diferencias con las cuales se constituyen. El autor reelaboró el concepto de autopoiesis propuesto por Humberto Maturana y Francisco Varela (2007), para quienes la autopoiesis era una característica específica de los seres vivos (organismos), una organización de procesos que producen los componentes que constituyen y especifican al sistema como una unidad:

El que los seres vivos tengan una organización, naturalmente, no es propio de ellos, sino común a todas aquellas cosas que podemos investigar como sistemas. Sin embargo, lo que es peculiar en ellos es que su organización es tal que su único producto es sí mismos, donde no hay separación entre productor y producto. El ser y el hacer de una unidad autopoiética son inseparables, y esto constituye su modo específico de organización (Maturana \& Varela 2007: 29).

Luhmann reelaboró el concepto en la medida que no sólo le otorgó la característica propuesta por Maturana y Varela a los organismos, sino que también se la otorgó a los sistemas de conciencia y de comunicación (Corsi et al. 1996). Luhmann hizo énfasis en las operaciones del sistema (en la clausura operativa) y no en los elementos (Arnold et al. 2010). Para Maturana y Varela, respecto a los sistemas biológicos y para Luhmann, respecto a todos los sistemas, se diría que:

Todo sistema autopoiético es una unidad de múltiples interdependencias, cuando hay una dimensión en ella que es afectada, es como si arrastrara a todo el organismo tras de sí a experimentar cambios correlativos en muchas dimensiones al mismo tiempo (Maturana \& Varela 2007: 77).

Por ejemplo, la conciencia, lo mismo que la temporalidad, no es algo que exista como sustancia, sino un modo de operación que distingue el sistema psíquico, así como la mente es una propiedad operativa del cerebro y no se localiza en ningún punto concreto de éste (Jeeves \& Brown 2009). Como lo sostenían por las teorías localizacionistas del siglo XIX, sustenta- 
das por los frenólogos Gall (1758-1828), Spurzheim (1758-1832) y Kleist (1979-1981), quienes localizaban las funciones psicológicas, la mente, en diferentes regiones de la corteza cerebral, haciendo énfasis en lo topológico, lo espacial y lo estructural (Raichle 1999; Uttal 2001, 2002). Estas teorías, en la actualidad, han sido complementadas con observaciones científicas que sugieren que las funciones psicológicas son resultado del acoplamiento eléctrico del cerebro.

Asumir una postura sistémica constructivista, permite pensar los niños con VIH desde la diferencia. Concebirlos como seres diferentes del entorno que producen sus propias informaciones, su propio modelo de temporalidad, a pesar de recibir informaciones del sistema social, donde derivan otros modelos de temporalidad. La autopoiesis que se da en cada uno de los sistemas que conforman al niño es la base de su individualidad, porque ésta es indivisible, lo cual sugiere que los sistemas que lo conforman se interpenetran ${ }^{1}$, pero ninguno se puede reducir al otro, ni absorberse por el otro; cada uno utiliza un modo de comunicación diferente (Luhmann 1998). Dichos sistemas, por ser funcionalmente específicos, permiten la emergencia de condiciones comparables que se acoplan en la diferencia, siendo ésta el centro de la teoría luhmanniana en la estructuración de los sistemas de interacción.

Jacques Derrida, según Luhmann, considera que al usar (...) "la palabra Différance, tanto al hablar como al escribir -y en todo tipo de experiencia- es necesario poner señales y trasladarlas a otras situaciones" (Luhmann 2007: 52). Por lo tanto, la diferenciación implica variación, puesto que las distinciones se entienden como rupturas, giros, transformaciones que se suceden y que requieren transportarse en el tiempo. La idea de diferencia permite ver que se trata de comparaciones y oposiciones que deben ser separadas mediante selecciones y exclusiones, pero manteniendo las posibilidades de variación.

El aporte de los sistemas que conforman al niño en la construcción de la temporalidad no se concibe de manera jerárquica, ni tampoco se establecen jerarquías en cada uno de ellos. Por el contrario, se considera que cada uno es diferente y aporta a la construcción de la temporalidad desde su diferencia. Por ejemplo: el sistema psíquico requiere los procesos que se dan en el sistema como la percepción, la atención, para llevar a cabo su autopoiesis. La conciencia de los niños sobre el mundo es una construcción en la cual participan los procesos biológicos, físicos y químicos que se dan en el sistema biológico, en el cerebro, y también requiere del sistema psíquico, que les da sentido a las informaciones provenientes del sistema de comunicación, y trata dicha información como si efectivamente estuviese por fuera del niño. Como lo argumenta Luhmann:

\footnotetext{
${ }^{1}$ La interpenetración es un modo de acoplamiento estructural entre sistemas que desarrollan una coevolución, donde ninguno existe sin el otro (Corsi et al. 1996).
} 
El mundo percibido no es otra cosa que la totalidad de los 'valores propios' de las operaciones neurofisiológicas. Aunque la información que evidencia esto no llegue de la conciencia al cerebro, se filtrará sistemáticamente sin dejar ninguna huella (Luhmann 2005: 19).

Según la teoría de sistemas autorreferentes autopoiéticos con clausura operacional (TGSAu) propuesta por Luhmann, el sistema psíquico puede percibir sensorialmente, pero el sistema de comunicación sólo puede afectarse a través del sistema psíquico (Luhmann 1998: 83). Ambos son sistemas cerrados en el sentido que el sistema psíquico sólo produce conciencia y el sistema de comunicación sólo produce comunicación, entendiendo la comunicación no como transmisión. El sistema biológico (el sistema nervioso) por si solo no es capaz de percibir, requiere del acoplamiento estructural con el sistema psíquico, pero éste es capaz de percibir que el sistema biológico (sistema nervioso) viva y funcione. Frente a esto Luhmann sostiene que:

El sistema nervioso únicamente es capaz de autoobservación y en el ámbito recursivo de sus operaciones no puede entablar ningún contacto con el entorno: se entiende por sí que no puede operar fuera de sus propios límites. El sistema nervioso sirve para que el organismo se auto-observe en la perspectiva de circunstancias cambiantes, en la perspectiva de un modo de tiempo que aquí se podría designar como información. El sistema nervioso no tiene la capacidad de combinar en la sucesión continua de sus operaciones autorreferencia con heterorreferencia (Luhmann 2005: 22).

En esta forma, la comunicación como la propone Luhmann no puede ser entendida como transmisión de información de un niño como ser vivo operativamente clausurado a otro niño, que también lo es. La comunicación requiere de seres vivos capaces de conciencia. Por sí sola, la comunicación no es capaz de percibir, aunque sí pueda comunicar las percepciones. Por ejemplo, cuando un niño dice que ha escuchado que..., está comunicando sobre las percepciones en el sistema de comunicación, pero este sistema no puede percibir, requiere del sistema psíquico y éste a su vez requiere del sistema biológico que le sirve como soporte.

La postura constructivista no desconoce que la comunicación que se genera en el sistema de comunicación irrita el sistema biológico y el sistema psíquico del niño, pero se desconoce que dicha comunicación determina la manera como el niño construye la temporalidad. Al niño no le llega por medio de la comunicación la ansiedad de los padres, de los maestros, ni los sentidos subjetivos. Sólo le llegan estímulos, informaciones que él interpreta y a las cuales les otorga sentido mediante su sistema psíquico.

La teoría sistémica constructivista permite leer la temporalidad como el resultado de la construcción que hace el niño con VIH, como sistema autopoiético en el interior de sus sistemas también autopoiéticos y con clausura operacional. 
El sistema biológico involucra los procesos estructurales, biológicos, físicos y químicos que producen vida; el sistema psíquico involucra los procesos psicológicos, las funciones cognitivas como la sensación, la emoción, la memoria, la atención, la percepción y todos los procesos que surgen del acoplamiento de estos. Y el sistema social involucra las interacciones, las sociedades y las organizaciones.

\section{EL NIÑO CON VIH COMO RECEPTOR ACTIVO DE INFORMACIÓN Y CONSTRUCTOR DE SU PROPIO MODELO DE TEMPORALIDAD}

Cada niño está conformado por sistemas únicos, autónomos, como el sistema biológico y el sistema psíquico que incluye los procesos psicológicos (sensación, emoción, percepción, atención, memoria, pensamiento, lenguaje, aprendizaje...). Ambos sistemas se modifican con la información que les llega del sistema social, pero sin perder su individualidad, su identidad. La información del sistema social solo puede tocar el entorno de ambos sistemas.

Considerar la temporalidad como una construcción propia de cada cerebro, influida por el funcionamiento interno de éste, como lo propone Carlos Eduardo Vasco (2000), permite pensar que aquélla emerge de manera individual y particular en cada niño. Se podría inferir que la forma en que construye la temporalidad un niño con una enfermedad crónica, como es el VIH que produce cambios emocionales y conductuales, es distinta a un niño sin una afectación en su sistema biológico, lo cual no se evidenció en los resultados finales de la investigación (Sánchez et al. 2017).

Asumir al niño como constructor de sus propios modelos de temporalidad permite pensar, como lo aclara Vasco, que los modelos que éste construye no son una "representación" ${ }^{2}$ del proceso como "copia, reflejo, o semejanza" (Vasco 2000: 220). Se propone decir que el niño representa la temporalidad sólo si representar se entiende:

Como una manera de "tener presente" o de "hacer presente", a través de mi modelo actual, un proceso pasado, presente o futuro con algún propósito, de tal manera que yo pueda reconstruir etapas o fases previas o prever etapas o fases ulteriores de ese proceso para modular mi accionar inmediato o futuro (Vasco 2000: 221).

En este sentido, el autor plantea que:

Los modelos y las teorías conforman la realidad de cada uno de nosotros y la

\footnotetext{
${ }^{2}$ La postura representacionista que se critica en la actual propuesta, asume que los modelos de los niños son el reflejo de los modelos de sus padres, de sus pares, etc. como si el niño fuera un receptor pasivo de información y no un receptor activo. Si se concibe al niño según una postura representacionista, esto implica aceptar que éste recibe del sistema social los sentidos subjetivos, los modelos, y que éstos se instalan en el sistema vida (en el sistema nervioso del niño), lo cual en la neurociencia no tendría explicación.
} 
realidad que creemos compartir socialmente con otros. Con el tiempo, cada uno de nosotros, al desarrollar su pensamiento crítico y autocrítico, empieza también a distinguir la realidad de su realidad y a cuestionar si la comparte con otros o solo cree que lo hace (Vasco 2014: 28).

Este análisis va en la línea constructivista al pensar que el niño con VIH construye su propio "modelo" de la temporalidad en sus procesos biológicos y psicológicos, con las irritaciones, estímulos o informaciones que le llegan del sistema social. El modelo que el niño construye lo proyecta por medio de la "teoría" en el sistema social, entendiendo las teorías como "sistemas lingüísticos que configuramos para hablar sobre nuestros modelos" (Vasco 2014: 54).

Pensar que un niño con VIH construye su propio modelo de temporalidad, sugiere aceptar que el niño es capaz de resignificar las informaciones que le llegan del entorno y decidir selectivamente ante qué informaciones se abre y ante qué informaciones se cierra.

Los niños con VIH, a pesar de estar expuestos a que el virus penetre su sistema nervioso central (SNC), a que invada sus células y les produzca lesiones en el tejido cerebral (Tellechea \& Legido 2003); (Angelini et al. 2000) tienen la posibilidad de construir sus propias simbologías del mundo, de la realidad y de la temporalidad, en la medida que, de forma autónoma, tienen la posibilidad de abrirse de manera selectiva al medio, para recibir determinadas informaciones y mantenerse indiferentes ante otras.

Respecto a su sistema biológico, lo único que impediría que un niño con VIH pudiera construir su propia temporalidad sería que presentara un compromiso neuropsicológico a causa de una encefalopatía progresiva o una encefalopatía estática (Lovato et al. 1995; Czornyj 2006) o de otras infecciones bacterianas serias y oportunistas que ataquen su SNC (Muñoz 2005; Wachsler \& Golden 2002). ${ }^{3}$ Estas enfermedades, según la clasificación establecida a nivel mundial para categorizar las manifestaciones clínicas y el pronóstico de las personas con VIH, son propias de la etapa C (CDC 1994). Siendo esta la única etapa en la que los niños con VIH presentan manifestaciones neuropsicológicas, como dificultades globales en sus habilidades cognitivas, motoras, de lenguaje y sociales, y alteraciones neurológicas significativas que alteran su funcionamiento cotidiano (Mintz 1996; Czornyj 2006).

Otro factor biológico que impediría que un niño con VIH pudiera construir su temporalidad es que tenga comprometidas las estructuras neuroanatómicas que permiten la función psicológica de la memoria,

\footnotetext{
${ }^{3}$ Los niños con estos compromisos, propios de la etapa $C$ de la enfermedad, podrían construir sus propios modelos de temporalidad y expresarlos por medio del lenguaje que no podamos interpretar. Y quizás sus padres, su entorno cercano, los puedan interpretar por la cercanía con el niño. Es importante en una investigación intentar comprender cómo construyen la temporalidad los niños con encefalopatías, entre otras afectaciones del SNC, después de trazar una línea base con la actual propuesta investigativa.
} 
como el hipocampo, el lóbulo temporal medial, la corteza prefrontal. Como lo argumenta Vasco:

La memoria está siempre acompañada de la conciencia de la vivencia de antesdurante. La memoria es esencial para la cronología ${ }^{4}$. Quien no tenga memoria no puede pensar ni hablar de tiempo, y con quien no la tenga no se puede hablar de tiempo. En realidad, con quien no la tenga no se puede hablar (Vasco 2000: 225).

En este orden de ideas, para que un niño con VIH construya la temporalidad en términos biológicos, es importante un sistema nervioso (SN) sin afectaciones propias de la etapa $\mathrm{C}$, ya que el $\mathrm{SN}$ asocia la información que le llega al niño por medio de los receptores sensoriales, que son células programadas para la detección y procesamiento de un tipo de estímulo. Por ejemplo: al oído del niño le llega el estímulo en forma de ondas de presión acústica, por medio de los mecanorreceptores hasta las células ciliadas (cóclea), pero no le llega al niño una canción que le evoca el pasado; sólo le llegan ondas. Y un niño a partir de sus procesos biológicos (SN) y psicológicos es capaz de darle sentido a esa canción y decir que le evoca determinada emoción agradable de cuando tenía seis años. Otro niño podría decir que no le evoca nada, y otro podría decir que no escuchó ninguna canción.

Este ejemplo indica que sólo una parte básica del proceso biológico del niño con VIH funciona en términos de receptor, porque recibe estímulos del medio. Pero para que determinados estímulos sean procesados se requiere una apertura selectiva, autónoma, y aquí juega un papel básico la historia de vida de los niños con VIH, al igual que sus procesos psicológicos y sociales, para la construcción de la temporalidad.

Pensar que los niños que conviven con VIH pueden construir su temporalidad, implica no leerlos como sistemas receptores pasivos de sentidos subjetivos, como miembros dependientes, invisibles y en estado de inacabamiento, evaluados según tipologías referentes al patrón adulto (Reybet 2009), ni como seres que copian de otros la temporalidad y los "modelos y teorías" (Vasco 2014).

Pensar el niño con VIH en términos de receptor pasivo de información conduce a leerlo sólo como un sistema abierto al que le llegan todos los sentidos subjetivos del entorno, como si dichos sentidos subjetivos provenientes del sistema social pudieran penetrar su sistema nervioso. Sería desconocer que el organismo sólo recibe del sistema social informaciones (estímulos) y no sentidos subjetivos y que se abre y se cierra ante determinada información. El sentido lo otorga el niño por su sistema psíquico con las informaciones provenientes del sistema biológico, que a su vez recibe informaciones del sistema social.

\footnotetext{
${ }^{4}$ Para el autor la cronología se encarga del estudio del tiempo y la temporalidad; y la cronometría del estudio de la duración y de la coordinación temporal de los fenómenos.
} 
Asumir al niño como receptor pasivo implica leerlo según la teoría de sistemas abiertos de Ludwig Von Bertalanffy (1976), que hace énfasis en la espacialidad, en la jerarquía, en el antropocentrismo, en lo topológico, en la conexión, en la integralidad, en las redes, en la retroalimentación; donde el niño es una totalidad constituida por partes. En contraste con esta perspectiva, se propone la teoría que surge de la propuesta de la TGSAu, que aborda cada uno de los procesos que conforman al niño mediante diferenciación, es decir, según la comparación.

La TGSAu sustituye la diferencia tradicional entre el todo y las partes, por la diferencia entre sistema y entorno. Y aquí aparece la diferencia entre sistemas abiertos y sistemas cerrados. "Estos últimos se definen como casos límite: sistemas para los cuales el entorno no tiene ningún significado o que sólo tienen significado a través de canales específicos" (Luhmann 1998: 31). Según el autor, la física había comprendido que el universo, respecto a la energía, es un sistema cerrado "que no puede dar acogida a ningún tipo de input que no esté contenido dentro de sí mismo" (Luhmann 1998: 18).

Se recurre a la teoría de sistemas autopoiéticos propuesta por Luhmann, porque la diferenciación sistema/entorno "ofrece mejores posibilidades de análisis, y, sobre todo, una comprensión más exacta de la homogeneidad" (Luhmann 1998: 32). Esta teoría reconoce que el niño, como sistema, no puede existir de forma independiente de su entorno, pero aclara que en esa relación sistema/entorno el niño como sistema es capaz de poner un límite que lo distingue de lo que, como ambiente, no le pertenece. Cuando el autor habla de fijar un límite, no significa que el niño como sistema se aislé del entorno, sólo que el niño es capaz de diferenciarse de éste a partir de sus propias operaciones.

Esta teoría no desvaloriza el entorno ni recurre a la jerarquización. Para el autor, tanto el sistema como el entorno son imprescindibles, en la medida que no se puede dar un sistema sin una relación con el entorno, $\mathrm{y}$ tampoco un entorno sin sistema; surgen solamente juntos. Esta perspectiva teórica de Luhmann permite pensar el niño con VIH como un sistema cerrado, no en el sentido estricto de la termodinámica, sino en el sentido que el niño sólo se abre a determinada información y no la recibe de forma pasiva sino activa. Información que procesa por medio del sistema vida y del sistema psíquico.

Según la postura tradicional (teoría de sistemas abiertos), a nivel psicológico y social, los niños no están al mismo nivel de sus padres, de sus maestros, de su equipo de salud (porque las relaciones se asumen como jerárquicas). El niño no construye su mundo, su realidad, su temporalidad, sino que la representa a partir de la relación en red, de la retroalimentación, de la heteropoiesis, relación que establece con su entorno, y de la observación de otros sistemas de orden superior. Como si los padres o los maestros construyeran la temporalidad (sentido subjetivo) y el niño lo que hiciera fuera representarla. 
En la práctica clínica, se observó que leer al niño según la postura tradicional (de acuerdo con la teoría de sistemas abiertos), respecto a la totalidad o a las relaciones entre las partes, niega la posibilidad de concebirlo como un sujeto diferente del entorno $y$, al no diferenciarse respecto de éste, no podría concebirse como constructor de su mundo y de su temporalidad.

Para que el niño construya la temporalidad, se requieren unos procesos biológicos y psicológicos que les otorgan sentido a las incitaciones del medio [véase tabla 1].

TABLA 1. COMPARACIÓN ENTRE SISTEMAS ABIERTOS Y AUTORREFERENTES

\begin{tabular}{|l|l|l|}
\hline COMUNICACIÓN & SISTEMAS ABIERTOS & SISTEMAS AUTORREFERENTES \\
\hline Posición del observador & Externo & Interno \\
\hline Posición de los sujetos & Antropocéntricos & Entorno \\
\hline Construcción sistémica & Suma de partes & sistema/entorno \\
\hline Operaciones del sistema & acción comunicativa & Comunicación \\
\hline Selección de operaciones & Sujetos & Función \\
\hline Decisiones a partir de & Sujetos & Función \\
\hline Lugar del poder & externo - heteronomía & sistema - autonomía \\
\hline Reproducción & Heteropoiesis & Autopoiesis \\
\hline Centramiento & si - sujeto & multicéntrico-observador \\
\hline Jerarquización & Si & No \\
\hline Referencias & relaciones en red & Interacciones \\
\hline Diferenciación & partes- estructuras & sistemas-función \\
\hline Intercambio información & sistemas abiertos & sistemas autorreferentes \\
\hline Clausura operativa & No & Si \\
\hline Acoplamiento estructural & No & Si \\
\hline
\end{tabular}

FUENTE: Sánchez (2011)

Desde la perspectiva de Luhmann, cada sistema se desarrolla según la diferencia funcional, es autopoiético, maneja un tipo de informacion específica y aporta a la construcción de la temporalidad en la diferencia. Por consiguiente, los sistemas que conforman al niño son sistemas de sentido y están orientados por las funciones que los definen y los originan, al igual que son sistemas autopoiéticos; es decir, son sistemas que se comportan como sistemas abiertos y como sistemas cerrados, sin concordancia con las leyes de aislamiento de la termodinámica, son energética e informativamente dependientes del entorno -sistemas abiertos-, pero al producir y reproducir sus operaciones, se comportan como sistemas operativamente clausurados, es decir, como sistemas autopoiéticos.

Todo sistema autopoiético es una unidad de múltiples interdependencias, cuando hay una dimensión en ella que es afectada, es como si arrastrara a todo el organismo tras de sí a experimentar cambios correlativos en muchas dimensiones al mismo tiempo (Maturana \& Varela 2007: 77).

Para Luhmann (2005b):

(...) el ser humano se encuentra en el entorno del sistema social. Para poder observar algo esta teoría busca operaciones que constituyan sistemas y el ser 
humano no puede ser concebido como una operación. Desde esta óptica el concepto mismo de ser humano se vuelve problemático porque, justamente, eso que la tradición ha considerado como unidad debe ser pensado como cúmulo de diferencias. En este sentido, el ser humano no es un sistema, sino que está constituido por diversos sistemas, uno de los cuales resulta de fundamental importancia para la teoría de Luhmann, a saber: el sistema psíquico (Luhmann, citado por Galindo 2007: XXVIII).

Según la teoría propuesta por Luhmann, los tres sistemas no se comunican por medio de una red "topológica, espacial", no se conectan, no se interrelaciona el sistema biológico, psíquico y social, sino que se acoplan de manera estructural sin perder su individualidad. Luhmann define el concepto de acoplamiento estructural en los siguientes términos:

El acoplamiento estructural consiste en una adaptación permanente entre sistemas diferentes, que mantienen su especificidad; no se puede reducir un sistema social a los sistemas psíquicos ni viceversa. Los pensamientos de un sistema psíquico no son comunicaciones, sino eventos propios de la reproducción autopoiética de la psiquis, que estimulan o irritan el sistema de comunicaciones. La comunicación, por su lado, tampoco ingresa al fluir de pensamientos del sistema psíquico de Ego o de Alter. Su papel se limita a estimular, gatillar o irritar pensamientos en el sistema psíquico. Esto nos permite entender que una misma comunicación estimule pensamientos diferentes en distintos interlocutores. La comunicación no consiste en el traspaso de un determinado contenido de un emisor a un receptor, sino en la creación intersubjetiva de sentido, que delimita un sistema social (Luhmann, citado por Rodríguez 2005: 36).

Para que el niño con VIH pueda construir la temporalidad, las decisiones de los tres sistemas diferenciados se deben acoplar, sin que cada sistema pierda su identidad, lo cual podría explicar que un niño, a pesar de estar en contextos comunicativos de riesgo y de interactuar con otros sujetos con otras simbologías, pueda construir su mundo, su realidad, su temporalidad, sin perder su identidad.

Los acoplamientos estructurales son, por lo tanto, restrictivas con la influencia del entorno sobre el sistema. Las células solamente aceptan determinados iones (como sodio y calcio) a través de sus membranas, y rechazan otros (como cesio o litio) (Luhmann 2005b: 509).

En el mismo sentido, Luhmann recuerda que:

Los cerebros, con sus ojos y oídos, se acoplan únicamente en un rango físico muy estrecho con su entorno $-\mathrm{y}$, en todo caso, lo hacen por medio de sus propias operaciones neurofisiológicas-. Pero, precisamente por ello, hacen al organismo increíblemente sensible respecto del entorno. La restricción es condición necesaria a capacidad de resonancia, y la reducción de la complejidad es condición necesaria de la construcción de complejidad (Luhmann 2005b: 509).

Para Luhmann (1998), gracias a la distinción entre sistema y entorno, se gana la posibilidad de concebir a la persona como parte del entorno social 
de manera compleja y, a la vez, más libre que si se le concibiera como parte de la sociedad, puesto que el entorno, en comparación con el sistema, es el campo de distinción de mayor complejidad y de mayor desorden. Con esta visión sistema/entorno, se presenta una concepción particular de hombre, como lo expresa Luhmann:

(...) se conceden al ser humano más libertades en relación con el entorno, particularmente ciertas libertades de comportamiento irracional e inmoral. El ser humano no es ya una medida de la sociedad; es necesario descartar esa vieja idea del humanismo. ¿Quién podría sostener, seria y ponderadamente, que la sociedad puede aún configurarse a imagen y semejanza del ser humano? (Luhmann 1998: 201).

Luhmann sugiere que los sistemas, a partir de la diferenciación, hacen una selección, disminuyendo la complejidad en el sistema, y a partir de la función, el sistema realiza la clausura operativa, selecciona los elementos. "La clausura operativa trae como consecuencia que el sistema esté determinado a la autoorganización. Sus propias estructuras pueden construirse y transformarse únicamente mediante operaciones propias" (Luhmann 2007: 67).

En la teoría de sistemas autopoiéticos, el sistema, por medio de sus propias operaciones, se vuelve a sí mismo sistema. Además, dice Luhmann: "En general, se puede hablar de sistema cuando se tiene ante los ojos características tales que, si se suprimieran, pondrían en cuestión el carácter de objeto de dicho sistema" (Luhmann 1998: 27).

\section{EL APORTE DEL SISTEMA BIOLÓGICO, PSÍQUICO Y SOCIAL EN LA} CONSTRUCCIÓN DE LA TEMPORALIDAD EN NIÑOS CON VIH

El observar el problema de investigación desde una óptica diferente a la tradicional y el haber utilizado la teoría de Luhmann, que incorpora, por decirlo de algún modo, una psicología, y finalmente por aplicar esta teoría para interpretar la manera en que los niños con VIH construyen la temporalidad, permitió explicar cómo los tres sistemas, el biológico, el psíquico y el social, desde su diferencia funcional, aportan a la construcción de la temporalidad como proceso psicológico y confirmar que los niños no son receptores pasivos de información, sino receptores activos, que tienen la posibilidad, como sistemas autopoiéticos, de abrirse y cerrarse ante la información que proviene del entorno. Se entiende que en la comunicación que establece el niño con su sistema social no se da mediante una transferencia de los sentidos subjetivos, sino que el niño tiene la posibilidad de construir el sentido, a partir del acoplamiento estructural entre los sistemas que lo conforman y entre estos y el sistema social. Por tanto, los niños no reproducen el modelo mental de sus padres ni piensan como sus padres.

La temporalidad como proceso psicológico surge con el aporte del 
sistema biológico (sistema nervioso) desde el acoplamiento estructural, desde la comparación que se da entre los diferentes subsistemas del sistema biológico; el acoplamiento estructural es temporal, es acontecimiento, es simultaneidad y posibilita las referencias entre sistemas diferentes el biológico, el psíquico y el social, al igual que entre los subsistemas de cada uno de los sistemas.

Los niños con VIH naturalizan su enfermedad al convivir con ella desde el nacimiento; por ello, no hacen alusión al tiempo en relación con su sistema biológico: salud/enfermedad, sino que aluden a la temporalidad según el número de actividades, la motivación, las emociones y lo que le comunica su sistema social.

No se observó que fuera diferente la forma como construía la temporalidad un niño con VIH que no convivía con sus padres biológicos, al niño que estaba bajo el cuidado de unos padres sustitutos de bienestar familiar. En la investigación se observó que la situación biológica no determina la forma como los niños construyen la temporalidad, este determinismo hace parte del imaginario simbólico del sistema social del cual los niños son entorno.

Los niños, solo reciben del sistema social información, pero no reciben los sentidos subjetivos del equipo interdisciplinario, ni de sus padres y tienen la capacidad de decidir ante qué información se abren y ante qué información ser cierran. Tanto que una madre del estudio se encontraba cursando un cuadro depresivo severo y el niño no tenía ninguna sintomatología afectiva que condujera a pensar que estuviera haciendo un cuadro depresivo o ansioso, a pesar de que su madre biológica llevaba cinco años con sintomatología depresiva. Los niños a pesar de estar en entornos comunicativos de riesgo, son capaces de construir otras simbologías del mundo, y por tanto de la temporalidad. Los niños reciben del sistema social estímulos, pero los procesan en su sistema biológico y su sistema psíquico de manera diferente.

Se observó que las madres biológicas, sustitutas y el equipo de acompañamiento son quienes en su imaginario simbólico han estructurado la creencia de que el tiempo dura más en los niños cuando se sienten enfermos y dura menos cuando están aliviados; esta simbiosis entre la salud y la enfermedad con las relaciones de pre-orden en los niños, al parecer, son una construcción de los adultos. Surge el interrogante de si esta simbiosis entre el cuadro clínico y las relaciones de pre-orden, están presentes en los adultos por su conciencia de la enfermedad.

El aporte del sistema psíquico a la construcción de la temporalidad, es a partir de la motivación, la emoción, la memoria, la percepción, la sensación, como procesos psicológicos. Si un niño se encuentra motivado por una actividad y se le suspende, el tiempo es corto; si un niño se siente frustrado porque la mamá no lo deja salir a la calle y se debe quedar en la casa terminando tareas, el tiempo es largo. Y si un niño se siente triste, preocupado porque está lloviendo y la mamá se está mojando cogiendo café y se puede enfermar, el tiempo es largo esperando a que escampe. 
A nivel del sistema psíquico se observó que la memoria es un proceso psicológico necesario para que el niño pueda realizar distinciones, ir al pasado y anticipar el futuro, desde el presente. El niño es el observador del tiempo y la memoria le brinda la posibilidad de establecer distinciones.

El niño no es un receptor pasivo de información, en la relación sistema/entorno; de su entorno recibe activamente información, pero también puede comunicar activamente información. Según esta lógica, la comunicación es una operación temporal, sistémica, de dobles contingencias, que se guarda en la memoria del sistema social.

Los niños pueden construir la percepción del tiempo por medio del acoplamiento estructural en el sistema nervioso, pero la percepción por sí sola no es capaz de comunicar sus percepciones, requiere del lenguaje como ley propia del sistema de comunicación para mencionar en la comunicación sus propias percepciones como lo propone Luhmann (2005). Tanto la comunicación como la precepción se construyen, la percepción se construye en el acoplamiento entre el sistema biológico y el sistema psíquico, y la comunicación se construye en el sistema social. La construcción sugiere que puede tomar formas diferentes y connotar un sentido diferente según el punto de vista del observador. Ambos procesos son temporales, aparecen y desaparecen y lo único que queda son memorias y olvidos.

El sistema biológico aporta a la construcción de la temporalidad, por el tiempo biológico, el tiempo que se da a nivel del sistema nervioso, el tiempo de las neuronas, de los sistemas neuronales. Las estructuras del sistema nervioso se conectan espacial y topológicamente para dar paso a la emergencia de los procesos psicológicos, se deben acoplar, entendiendo el acoplamiento como ese proceso temporal, abstracto, complejo que se requiere para que emerja la comunicación entre la mente y el cuerpo.

El niño construye su propia certeza de la temporalidad en sus operaciones neurofisiológicas de su sistema biológico (procesos biológicos) y de su sistema psíquico (procesos psicológicos), con las irritaciones provenientes del sistema comunicación (sistema social) y luego externaliza su modelo en el sistema social por medio de la comunicación.RM

\section{REFERENCIAS}

Angelini, L., Zibordi, F., \& Triulzi, F. (2000). Age-Dependent Neurologic Manifestations of HIV Infection in Childhood. Neurol Sci, 21, 135-142.

Arnold, M., Thumala, D., \& Urquiza, A. (2010). Autopoiesis como material explosivo en la teoría social contemporánea. In: Memorias X Congreso de la Federación Española de Sociología. Pamplona: Universidad Pública de Navarra.

Bertalanffy, L. V. (1976). Teoría General de los Sistemas. México DF: Fondo de Cultura Económica.

CDC. (1994). Revised Classification System for Human Immunodeficiency Virus Infection in Children < 13 Years of Age. MMWR, 43(RR-12).

Corsi, G., Esposito, E., \& Baraldi, C. (1996). Glosario sobre la teoría social de Niklas Luhmann. México DF: Universidad Iberoamericana, ITESO, Anthropos. 
Czornyj, L. (2006). Encefalopatía en niños con infección por virus de inmunodeficiencia humana de transmisión vertical. Rev Neurol, 42(12), 743753.

Galindo, J. (2007). Prólogo. In: N. Luhmann, La sociedad de la sociedad. México DF: Herder.

Jeeves, M. \& Brown, W. (2009). Neurociencia, psicología y religión. Madrid: Verbo Divino.

Lovato, M., Caldwell, M., Ng, P., \& Oxtoby, M. (1995). Encephalopathy in Children with Perinatally Acquired Human Inmunodeficiency Virus Infection. Pediatric Spectrum of Disease Clinical Consortium. Journal of Pediatric, 126(5Pt1), 710715.

Luhmann, N. (1998). Sistemas Sociales. Lineamientos para una teoría general. Bogotá: Universidad Javeriana.

Luhmann, N. (2005). El arte de la sociedad. México DF: Universidad Iberoamericana, Herder .

Luhmann, N. (2005b). El derecho de la sociedad. México DF: Herder, Universidad Iberoamericana.

Luhmann, N. (2007). La sociedad de la sociedad. México DF: Herder, Universidad Iberoamericana.

Maturana, H., \& Varela, F. (2007). El árbol del conocimiento. Santiago de Chile: Editorial Universitaria.

Mintz, M. (1996). Neurological and Developmental Problems in Pediatric HIV Infection. The Journal of Nutrition, 126, 2663-2676.

Muñoz, T. (2005). Virus de inmunodeficiencia humana y complicaciones neurológicas (actualización). Revista de Pediatría Electrónica, 2(1), 62-69.

Raichle, M. (1999). Modern Prenology: Maps of Human Cortical Function. Ann NY Acad Sci 882, 107-118.

Reybet, C. (2009). Construyendo un objeto de investigación desde la antropología que articule: género, escuela y primera infancia. Aljaba, 13

Rodríguez, D. (2005). Invitación a la sociología de Niklas Luhmann. In: El derecho de la sociedad. México DF: Herder, Universidad Iberoamericana.

Sánchez, C. (2011). El currículo: un sistema/entorno auto/heterorreferente: una perspectiva para la formación de los Médicos Veterinarios Zootecnistas de la Universidad de Caldas (Tesis doctoral). Manizales: Universidad de Caldas.

Sánchez, J., Vasco, C. \& Restrepo, F. (2017). La construcción de la temporalidad en niños y niñas con VIH. Manizales: Universidad de Manizales.

Tellechea, N. \& Legido, A. (2003). Acquired Immunodeficiency Syndrome by Vertical Transmission: Neurological Disorders. Rev Neurol, 36(3), 255-263.

Uttal, W. (2001). The New Prenology: The Limits of Localizing Cognitive Processes in the Brain. Cambridge: MIT Press.

Uttal, W. (2002). Précis of the New Prenology: The Liits of Localizing Cognitive Processes in the Brain. Brain and mind, 221-228.

Vasco, C. (2000). El problema del tiempo. Medellín: Universidad Nacional de Colombia.

Vasco, C. (2014). La Teoría General de Procesos y Sistemas. In: Documentos de la Misión de Ciencia, Educacion y Desarrollo, tomo segundo. Bogotá: Ministerio de Educación.

Wachsler, J. \& Golden, C. (2002). Neuropsychological Consequences of HIV in Children: A Review of the Current Literature. Clinical Psychological Review, 22, 441-462. 
SOBRE LA AUTORA

Jessica Sánchez es docente, investigadora y coordinadora de la Unidad de Investigaciones del Programa de Psicología de la Universidad de Manizales. Ph.D. en Ciencias Sociales, Niñez y Juventud del Centro de Estudios Avanzados en Niñez y Juventud Universidad de Manizales-CINDE. Magíster en Desarrollo Infantil y Psicóloga de la Universidad de Manizales. Realizó Curso Universitario en Psicopatología en la Universidad de Barcelona.

CONTACTO

jsanchez@umanizales.edu.co

Recibido: diciembre 2016

Aceptado: abril 2017 